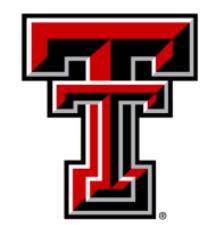

TEXAS TECH UNIVERSITY

Libraries"

\title{
The Potential of Mindfulness in Managing Emotions in LIBRARIES
}

\section{The Texas Tech community has made this publication openly available. Please share how this access benefits you. Your story matters to us.}

\begin{tabular}{|l|l|}
\hline Citation & $\begin{array}{l}\text { Quinn, B. (2017), "The Potential of Mindfulness in Managing } \\
\text { Emotions in Libraries", Emotion in the Library Workplace (Advances } \\
\text { in Library Administration and Organization, Vol. 37), Emerald } \\
\text { Publishing Limited, pp. 15-33. https://doi.org/10.1108/S0732- } \\
\text { 067120170000037002 }\end{array}$ \\
\hline Citable Link & $\underline{\text { http://hdl.handle.net/2346/73787 }}$ \\
\hline Terms of Use & $\underline{\text { CC-BY }}$ \\
\hline
\end{tabular}


The Potential of Mindfulness in Managing Emotions in Libraries

The Potential of Mindfulness in Managing Emotions in Libraries

\section{Brian Quinn}

Texas Tech University 
The Potential of Mindfulness in Managing Emotions in Libraries

\section{Structured Abstract}

Purpose: The purpose of the study is to investigate the potential of utilizing mindfulness practices to regulate emotions in libraries. Libraries are emotionally stressful environments characterized by continuous change and uncertainty. Working with the public and with colleagues can lead to emotional strain and exhaustion. Mindfulness offers librarians a means to achieve a degree of emotional control so they do not identify with emotions, allowing them to focus more fully on their work.

Design/Methodology/Approach: This study examines the scientific research that has been conducted on mindfulness and the effect it has on emotions. The research is drawn from the fields of psychology and related fields such as medicine. The findings are applied to the library field to examine what the potential implications might be.

Findings: Psychological studies have shown that mindfulness has the potential to effectively manage emotions in the workplace and in organizational settings. Mindfulness practices help individuals manage emotions by a process of attuning to and dis-identifying with affective content, leaving them free to concentrate on the task at hand.

Originality/Value: Psychological science has found mindfulness to be useful for managing emotions. These findings have potential implications for libraries. By applying mindfulness to the library setting, this study provides librarians with an effective strategy for regulating emotions and coping with workrelated stress. 
The Potential of Mindfulness in Managing Emotions in Libraries

Introduction

Despite the popular stereotype of the occupation of librarianship as being quiet, low-key work characterized by order and routine, there are a variety of factors that make the work emotional and at times stressful. The field is undergoing rapid technological change that requires librarians to continually keep up with and learn new systems and applications leaving them in a perpetual state of Future Shock. Roles and responsibilities change continuously as libraries transition to a digital world and accompanying this upheaval is a specter of obsolescence, disintermediation, and outsourcing that hangs over the workplace.

Technology has also raised expectations for around the clock availability and communication, such that time off from work often requires continually monitoring email or phone messages so that it might feel that one has never really left the office. The sheer number of technological applications that librarians find themselves involved with leads to pressures to multi-task, adding to emotional strain and making it difficult to maintain focus on one task at any given time. This can lead to frustration and continuous distraction, a sense that one is not able to attend to any task long enough to complete it satisfactorily.

At the same time, libraries are being squeezed by financial pressures to streamline and downsize and at the same time provide high quality collections and services. Librarians are often caught in the middle, trying to explain why they cannot afford to purchase everything their users need. In recent years, a new emphasis on assessment and accountability has arisen in which all librarian initiatives and activities and the results of those activities are scrutinized, counted, and measured in minute detail. Librarians may feel that they are in a glass bowl in which every activity they engage in is being watched and evaluated. 
The Potential of Mindfulness in Managing Emotions in Libraries

In addition to environmental factors, people also contribute to the emotional nature of library work. Many librarians work with the public, and this can involve emotional labor (Matteson, Chittock, \& Mease, 2015) in which librarians are expected to manage their emotions to convey an approachable, positive, upbeat persona that shows concern for users and interest in meeting their needs. When faced with difficult or demanding users, librarians are expected to maintain emotional neutrality and to be courteous, professional and helpful. They must do this despite any emotions that they may actually be experiencing, requiring them at times to suppress emotions that do not fit the public image that their work requires them to display. The stress that this creates within librarians renders their work emotional labor because they have to work at controlling their emotions in a way that they would not be required to do when not at work.

The emotional labor that is characteristic of library work is not limited to those librarians who interact with users. All librarians, including those who work in technical services that do not work with the public on a regular basis, must work with colleagues, supervisors and subordinates. In order to be successful, librarians must get along with their supervisors, be respectful and polite to them, and do as they request. They must do this despite how they may actually feel, which means that their outward expression of emotions must conform to the expectations of their supervisors if they are to advance in their careers and avoid negative performance evaluations. Similarly, all librarians must work with their colleagues and present a reasonably predictable persona that is cooperative and respectful and emotionally neutral. All of these interpersonal relations within the workplace require some degree of effort or work to maintain and hence may be considered forms of emotional labor.

The library field emphasizes the expression of positive emotions and the suppression of negative emotions in the workplace. Over time, the forced expression of positive emotions through superficial display or constantly attempting to maintain a façade of neutrality can result in a condition known as emotional exhaustion, in which the person feels that they are emotionally depleted and do not have the 
The Potential of Mindfulness in Managing Emotions in Libraries

affective resources to continue to maintain the persona expected of them. Similarly, the forced suppression of negative emotions can result in physical illness (Gross \& Levenson, 1997). The inability to manage emotions can thus have psychosomatic consequences that can lead to physical illness, absenteeism, and burnout.

Chronic workplace stress also creates psychological problems. Affect and cognition are closely linked, so that when one is emotionally distressed, one's cognitive functioning may be similarly compromised (Chepenik, Cornew, \& Farah, 2007). When the mind is under stress, it has a tendency to race and produce internal noise or mental chatter. A monologue occurs that is often irrational and nonsensical consisting of snippets of conversation, songs that keep repeating, memories, fantasies, and associations. The ego babbles on endlessly in an effort to remove one from the discomfort of the work situation. This makes it difficult for librarians to focus on work, to reason, and to plan rationally. The lack of focus can manifest in various ways, often hijacking short-term memory, so that one has no recollection of what one just did. A librarian may be introduced to someone, and a minute later, not recall their name. After reading an email or a memo, one may not recall the content. Walking into a room, one may have forgotten what it was that one went there for. These memory lapses, originating as a reaction to stress, then serve to compound the stress by rendering one cognitively impaired at the very time when one needs to be attentive and on task.

The result is that a librarian can spend a significant part of the work day physically present but mentally lost in an emotional and cognitive jumble. Emotional and cognitive stress not only contribute to chronic absent-mindedness, but they can feed one another and spiral, resulting in poor task performance, illness, and lost work time. Tasks that require in-depth sustained attention may end up, out of necessity, being performed in a perfunctory, superficial way. Lacking is any sense of accomplishment or satisfaction stemming from having done a job well and completely and achieving a sense of closure, along with the emotional satisfaction that comes from such success. 
The Potential of Mindfulness in Managing Emotions in Libraries

\section{The Role of Mindfulness}

The strong service orientation of libraries requires librarians to manage their emotions and engage in emotional labor. Librarians in public services have to contend with a variety of users, some of whom can be difficult and demanding, and all librarians have to work with "internal customers," in the form of colleagues. This process of emotional labor, of having to suppress negative emotions and superficially display positive emotions despite how one actually feels, can lead to emotional exhaustion.

A growing body of research suggests that mindfulness offers promise as a practice that can serve to counter some of the negative effects of emotional labor and may help to prevent librarians from burning out emotionally (Hülsheger, Alberts, Feinholdt, \& Lang, 2013). Mindfulness is the practice of bringing one's attention to the present and monitoring one's feelings, thoughts, and sensations nonjudgmentally as they occur in awareness. It does not require elaborate special training or techniques and may to some extent occur naturally in individuals without any background in mindfulness or meditation, a phenomenon that psychologists term "trait mindfulness" (Niemiec et al., 2010). It also occurs periodically in all individuals in the form of a temporary state that they enter in to in which they are attuned to their mind and body along with the usual situational awareness. Most of us have had brief periods when we switch off auto-pilot and are completely in the moment and able to experience it fully without distraction.

Libraries, like other work environments, require that librarians maintain emotional self-control as they conduct their work in order to establish an optimal working environment free of drama and conflict. A demeanor of neutrality and pleasantness is expected of employees even when they may feel exhausted, distracted, or overwhelmed. Negative emotions must be suppressed in order to keep with the general expectations by employers that librarians maintain a positive atmosphere. Emotional selfcontrol requires effort, in the form of emotional labor, and self-control can become depleted over time. 
The Potential of Mindfulness in Managing Emotions in Libraries

The practice of mindfulness helps to increase the level of self-control of librarians in the workplace by helping to replenish low reserves of self-control so that librarians have sufficient self-control resources to allow them to do their work without losing emotional control, mental clarity, and effective decision making.

An experiment conducted by psychologists demonstrates this. Psychologists asked a group of subjects to watch a series of videos designed to elicit disgust while maintaining neutral facial expressions, so that they would be required to exert emotional control over themselves. They were then asked to complete tests that required that they measure their level of attention and inhibition during the performance of connect the dots and crossing out letters tasks. The results indicated that subjects who were asked to suppress their emotions and who then practiced mindfulness meditation performed as well as a control group who viewed the videos but were not asked to suppress their emotions (Friese, Messner, \& Schaffner, 2012).

Mindfulness can be helpful in managing emotions because it encourages one to be aware of and observe one's emotions as they arise without getting caught up in them or reacting to them. One of the most common mindfulness practices is to focus on the breath and use it to center one's self. Then as emotions arise in awareness, one simply notes that by labelling them "anger," "frustration," "sadness," "fear," etc., and one then returns one's awareness back to the breath. One's breathing serves to anchor awareness in the present moment and helps to keep it from getting distracted by internal or external stimuli and ensnared in the passion of the moment. Engaging one's witness consciousness so that one can observe emotions without getting trapped and swept away by them can be helpful in another way. It can help one to realize that these emotions that are experienced are not actually part of one's self. Rather, they are fleeting states that do not have any lasting effect on one if one does allow one's self to be seduced and captured by them. Through this process of dis-identification, the power of emotions is reduced and the mind quiets down. One arrives at the insight that emotions are ephemeral and 
The Potential of Mindfulness in Managing Emotions in Libraries

transitory and something that can be experienced, noted, and dismissed rather than feared, suppressed, denied, or acted upon. In this way, mindfulness helps to cultivate self-regulation and minimize habitual and reactive emotional responses that trigger chains of associations and set the stage for escalation.

Mindfulness practice reveals that emotions do not have to be fought with or struggled with in order to manage them effectively. Forcefully trying to rid the mind of emotional states simply creates more internal strife and compounds the stress. Engaging in emotional suppression often has the opposite effect. It requires both energy and effort and can result in the emotion returning in a magnified form so that it has even greater force than when it was first experienced. Allowing emotions to surface and accepting them into awareness without judgment until they diminish and pass is much more effective at reducing their intensity and extinguishing them than attempting to control and suppress them (Philippot \& Heeren, 2013).

The practice of mindfulness not only contributes to emotional self-regulation, it also builds emotional resilience. By dis-identifying with negative emotions and realizing that they are not the same as one's self, the self is then protected and along with it the individual's sense of self-worth. Work situations in which one is put under pressure to perform, such as delivering a speech, can be helped through the practice of mindfulness because the mindful librarian is able to distance him- or her-self from the negative emotions that may arise and not choke under pressure. Creating this emotional distance provides the librarian with a more realistic, grounded, and stable view of reality that is free of emotional distortion and enables him or her to feel in control emotionally.

\section{The Effects of Mindfulness}

Approaching work mindfully helps to prevent emotional exhaustion or burnout, as it is commonly referred to, by reducing what psychologists refer to as surface acting. This behavior is a form of emotional regulation that librarians and other workers in service-oriented occupations engage in 
The Potential of Mindfulness in Managing Emotions in Libraries

order to meet the demands of their work to display positive emotions even though they may not actually feel them (Semmer, Messerli, \& Tschan, 2016). Surface acting creates emotional stress in several ways. It requires the librarian to simultaneously suppress any authentic negative emotions that she or he feels, and at the same time, to make a conscious, deliberate effort to present a positive emotional façade. The contradiction between the two emotional states creates internal emotional dissonance within the librarian. In some cases, the librarian may worry that the user or colleague may detect the superficial performance and become upset at the librarian's lack of sincerity. The combination of suppression, effort, and dissonance together set the stage for emotional exhaustion.

Negative emotions are not only problematic in service-oriented occupations that require emotional labor, they can be a detriment if they interfere with one's work. Emotional interference can reduce the librarian's ability to focus on work tasks and make him or her less effective and less productive. Negative emotions can capture attention and serve as a drain on limited attentional resources. Mindfulness can help to reduce the monopolization of attention by negative emotions because it trains one to attend to these emotions, recognize them as impermanent and fleeting, and allows one to return one's attention to the present moment and the task at hand without spending a long period of time ruminating over or processing these emotions (Ortner, Kilner, \& Zelazo, 2007).

Dwelling on the negative aspects of a situation and exposing oneself to negative emotions over a prolonged period can deplete one's mental and physical coping mechanisms and resources. Mindfulness helps to boost resilience and enhance the immune system by minimizing the exposure to negative emotional states. With practice, a librarian can learn to enter into a mindful state which would make it easier to recognize and dismiss any emotional reaction so that it is less disruptive to his or her work and so it is not followed by an extended period of immersion in potentially harmful emotional states. In a study of employees of the Dow Chemical Company (Aikens et al., 2014), participants were taught mindfulness techniques and were administered the Connor-Davidson Resilience Scale which 
The Potential of Mindfulness in Managing Emotions in Libraries

measures a person's ability to handle negative emotions, adapt to change, and ability to actively find solutions to problems. Mindfulness practitioners were able to achieve a twelve percent increase in resilience along with a twenty-three percent decrease in stress.

Mindfulness can play a role in reducing impulsive behavior in the workplace. Knee-jerk decision making and doing things without thinking are common in libraries and other stressful work settings. It is not unusual to find colleagues who are prone to blurting out comments in meetings and adopt a shoot from the hip mindset that leads them to make poorly considered decisions. Impulsive purchasing can also occur in collection development, in which librarians will not take the time to think through carefully the potential usefulness of a product or service and succumb to the sales pitch of a vendor or a sophisticated marketing strategy. Impulsive behavior may be mistaken for decisiveness and getting things done. The practice of mindfulness can temper impulsive tendencies by preventing the librarian from getting swept up in emotions and by seeing them as temporary. One's own mind and how it reacts becomes the focus of attention rather than identifying with emotionally charged content (Papies, Barsalou, \& Custers, 2012).

An important aspect of mindfulness is its ability to affect organizational citizenship behavior. This can be defined as approaching work conscientiously, exhibiting a willingness to endure organizational shortcomings without excessive complaining, and behaving in a courteous and altruistic way toward colleagues (Podsakoff, MacKenzie, Moorman \& Fetter, 1990). The willingness of employees to assist their colleagues and support them in a team effort is important to maintaining the optimal functioning of the organization. Although most workplaces are competitive environments, the organizations can become dysfunctional and aversive if colleagues engage in open conflict with one another. Librarians who are so competitive that they seek to advance their careers at the expense of their colleagues are as much a liability as an asset to the goals of the organization. Engaging in backstabbing behavior or sabotaging the projects of others make the library less effective. Practicing 
The Potential of Mindfulness in Managing Emotions in Libraries

mindfulness can be helpful in cultivating positive prosocial emotions toward one's colleagues and minimizing the effect of narcissistic and sociopathic tendencies in colleagues who may view climbing the career ladder as more important than being a team player.

In order to investigate the effects of mindfulness on prosocial behavior, a group of psychologists conducted an experiment in which half of the subjects participated in an eight-week course in mindfulness meditation and the other half did not (Condon, Desbordes, Miller, \& DeSteno, 2013). Participants were then scheduled to visit the lab ostensibly to run some tests, but in reality to conduct the experiment. When a participant arrived at the lab and was seated in the waiting area, a confederate experimenter approached the waiting area on crutches wearing a walking boot and wincing in pain. All the seats in the waiting area were taken and the participant had to make a decision to give up his or her seat so that the person with crutches could sit down, or to remain seated.

The experimenters found that the participants who had received the mindfulness training were more than five times as likely to offer their seat to the injured person as those who did not. The finding is even more surprising given that the sufferer was a stranger to the participant, and that the two other people occupying chairs in the waiting room were confederates who were instructed to completely ignore the injured person, thus creating social pressure on the participant to ignore the person. The experiment shows that mindfulness can contribute to compassionate behavior in real-world situations, behavior that is likely to transfer into other settings such as the workplace. Practicing mindfulness in the workplace can help contribute to organizational citizenship by making librarians more empathetic and supportive of their colleagues.

How Mindfulness Works

One of the reasons that mindfulness is effective in promoting positive prosocial states is that it helps to eliminate negative emotional states. Neuroscientists have found that one way that it does this is through 
The Potential of Mindfulness in Managing Emotions in Libraries

labeling of affect (J. D. Creswell, Way, Eisenberger, \& Lieberman, 2007). One aspect of mindfulness requires practitioners to allow emotions to arise in awareness and then to label them (e.g. "anger," "sadness," "frustration," etc.) as they become aware of them. This process of labeling emotions trains librarians in how to recognize emotions, which is something that not everyone has the ability to do. Labeling allows librarians to treat their emotions as objects, allowing them to objectify them. It acts to defuse them of their power and creates a degree of psychological distance so that the user is not caught up in them and does not get swept away by them.

If there is less emotional reaction on the part of the librarian, that would suggest faster recovery from emotional reactivity. By bringing attention to the emotion, the librarian undergoes exposure to it, regarding it with acceptance rather than reactivity or aversion. By treating negative or unpleasant emotions with acceptance, the usual negative reaction of avoidance is gradually extinguished. A librarian practicing meditation learns to enter into a deeply relaxed state both physically and mentally, so that any emotions that are encountered and experienced in this calm state are not experienced with the usual conditioned response of fear or negativity (Hölzel et al., 2011). Experiencing negative emotions in this state causes them to lose their negative affective charge so that they are no longer regarded as overwhelming or intolerable. Practicing in this way trains the librarian to remain unattached to negative emotions when they arise in stressful situations.

Attending to the present helps the librarian to manage negative emotion. Many negative emotions are generated by a process of ruminating about the past or anxiously anticipating future events that have not yet occurred. This creates frustration and depression because the past cannot be changed and the future is unknowable. Over time, a sense of futility may set in because, at some level, the librarian realizes that the mental upheaval is unproductive or counterproductive. The present, which is within control, is typically ignored. Practicing mindfulness situates awareness in the present moment so that the librarian is not distracted by mental time travel to the past or future. Stressful emotions and thoughts may 
The Potential of Mindfulness in Managing Emotions in Libraries

still arise, but with practice the librarian learns to detach from them and sees them as passing, temporary states and that elaborating on them is not helpful.

The practice of mindfulness helps the practitioner to cope better by creating a shift from emotionfocused coping to problem-focused coping (Charoensukmongkol, 2013). People who are not trained in mindfulness will ordinarily attempt to manage stress by reacting to stressful events emotionally and replaying these events mentally over and over. They may try to escape the unpleasantness through daydreaming or fantasy, or in some cases engage in various forms of substance abuse in an effort to cope. In contrast, the mindful librarian will be less likely to engage in avoidance and be more situated in the present to focus on the problem that is creating the stress, attempting actively to solve it rather than avoid it.

Without emotions impinging on it, the mind is clear to function more effectively and to view one's environment more realistically. The mindful librarian has a greater sense of what psychologists refer to as self-efficacy. This is the belief that one is capable of being effective and succeeding, a feeling that one has the resources to effectively cope with whatever demands one is facing. It involves a positive interpretation of the work situation and sensing that one has potential and that it can be realized. The feeling of confidence allows the librarian to face whatever work-related issue he or she may be facing without feelings of inadequacy or doubt. Believing in one's self motivates the librarian to address the problem directly without wasting energy on emotional upheaval or dysfunctional responses, such as feeling pessimistic and helpless. Clarity of mind leads to more constructive and positive responses to work-related issues because the mind is less distracted by negative emotions that consume mental energy (Luberto, Cotton, McLeish, Mingione, \& O’Bryan, 2014).

With practice, the librarian who engages in mindfulness learns to abandon previously held conception of his or her self as a body with a mind. Rather, there is a gradual realization that this 
The Potential of Mindfulness in Managing Emotions in Libraries

conception is simply the result of identifying with the body and mind because we experience them in the form of sensations, feelings and thoughts. Once the librarian learns that the body and mind can be observed and objectified without identifying with them, there is an increasing understanding that what was formerly believed to be the self is not these objects of awareness, but the phenomenon that observes them, awareness itself. The more the librarian begins to dis-identify with feelings, thoughts, and sensations, the more she or he is able to adopt witness consciousness, the perspective of the observer that is capable of watching mental content, the ever-changing stream of consciousness, without getting caught up in it or swept away by it (Khisty, 2010). Over time, it becomes easier for the librarian to engage this witness consciousness when faced with difficult situations and to observe the associated emotions rather than get attached to stress-related emotional states. This allows the librarian to see emotionally stressful work situations more clearly and act on them in an appropriate way.

Adopting the perspective of the witness rather than reacting emotionally gives the librarian brief time to pause and consider what might be appropriate action strategies, if any. It allows she or he to consider if there may be any positive aspects to the situation and if there are, to appreciate them. Approaching negative emotions with an attitude of openness, curiosity, and acceptance may help to defuse them of their distressing quality and also allow the librarian to reappraise the situation in a positive way. Witnessing emotions with a perspective of equanimous neutrality rather than aversion or avoidance not only helps to deflate negative emotions but also enables the librarian to respond more flexibly without immediately reacting (Lindsay \& Creswell, 2015).

In addition to this temporal element, a spatial element is also involved. In witness mode, the librarian is able to achieve a degree of distance from his or her emotions. That is, the librarian can observe the emotions mindfully, and realize in the process that the emotions are separate from the self. This creates the realization that one is not one's emotions, that they are separate. This in turn fosters a sense of mindful distance or detachment, an understanding that "these feelings are not really me, and are in 
The Potential of Mindfulness in Managing Emotions in Libraries

some way apart from me." Mindfulness thus helps to create psychological distance from the emotions, helping to objectify them and allow them to be regarded as "something other" than me. Creating distance from emotions allows the librarian to see them in perspective and not be drawn into them and get caught in emotional escalation.

The Social Effects of Mindfulness

Psychologists have found that this distancing or detachment can transfer to social situations, such as the workplace. They conducted an experiment in which a group of subjects participated in an economic game that required them to interact socially and that was designed to generate interpersonal emotional responses from the participants (Grecucci et al., 2015). The game is played by giving two players a sum of money and having one person offer proposals to divide the money between them. If the other person accepts the offer, the money is divided between them. If the person rejects the offer, neither player receives anything. Unfair offers typically result in rejection and an expression of negative emotion toward the proposer such as frustration or anger. The higher the percentage of rejections the less the regulation of social emotions occurred.

The results of the study indicated that meditators engaged in less emotion-based rejection than those participants in the control group. This suggests that they were better able to manage their emotional reactions through the process of detaching from them mindfully. Instead of becoming irritated at the proposer for making unfair offers, the meditators accepted the behavior in a less judgmental way than the control group. They were thus able to demonstrate that they could adopt a non-reactive response to selfish behavior and mistreatment and not get caught in a negative spiral of emotional exchange that would typically accompany such an interaction in the workplace.

Mindfulness allows the librarian to create a buffer of awareness, a level of distance from the emotion that acts as a check on the impulse to retaliate and escalate. It provides a space in which the 
The Potential of Mindfulness in Managing Emotions in Libraries

librarian can decide whether retaliation is the best way to behave and to face directly feelings of irritation with openness and acceptance (Smyth, 2012). Mindfulness can prevent the librarian involved in a disagreement or conflict with a colleague to jump to the defense of the self because mindfulness practice teaches the librarian that the self is not simply a bundle of emotions but something apart from that which is capable of distancing and observing emotions. They realize that the actual self is a form of awareness that can expand to become larger than their emotions without having to identify with them. The self then is no longer directly identified with the conflict and can disengage and divest from it more readily.

\section{Discrimination and Non-Discrimination}

Librarians who practice mindfulness can recognize the expression of emotions better than those who do not (Kemeny et al., 2012). Recognizing and being able to discriminate between emotional states, such as when others are experiencing difficulty in the workplace, is important because it allows the librarian to respond appropriately, in a collegial and supportive way. The inability to recognize emotions in others can lead to insensitive behavior on the part of colleagues and inappropriate responses that make the library environment more stressful. Good communication, including interpreting and expressing emotion appropriately, is important for an effective work environment.

Practicing mindfulness can also help counter the pervasive use of stereotypes in the workplace. Librarians must contend with assumptions that they make about each other that can become obstacles to working together smoothly and collegially. This goes beyond obvious differences like race and gender. For example, one of the more common biases that librarians encounter is that older colleagues are technophobes who prefer working with print sources. At the same time, younger colleagues may be seen as being tech savvy but shallow and not interested in books or culture. Similarly, there may be bias expressed toward colleagues who may be absent from work a lot because they have children to care for 
The Potential of Mindfulness in Managing Emotions in Libraries

and require other librarians to cover for them. Labeling and prejudice can include patrons as well as colleagues, especially for those who work in public services areas like reference, reserve, and circulation.

New research suggests that librarians who approach their work mindfully may develop a greater level of psychological flexibility that helps keep them from behaving in discriminatory ways. A group of subjects were recruited to participate in a trust game in which they were each given fifty dollars and instructed to accumulate as much money as possible by the end of the game. The individual accumulating the highest dollar amount was given a prize. The subjects first listened to a ten-minute mindfulness meditation audiotape, while a control group listened to a tape describing the English countryside. The subjects were then exposed to pictures of an equal number of Black, White, and Asian faces. They were finally asked to decide how much money they would give to each of the persons pictured and trust that the persons would give the money back. Participants in the control condition gave Whites $14 \%$ more money than Blacks, while those who listened to the meditation gave only $3 \%$ more. The experimenters believe that the practice of mindfulness helped to lower the number of automatic associations between race and negativity before it could be expressed (Lueke \& Gibson, 2016). These findings suggest that librarians who practice mindfulness may not be as prone to engage in the same degree of workplace stereotyping as those who do not.

Mindfulness improves social relationships in the workplace in other ways. In the library, good communication and collaboration depends on accurately interpreting the emotional cues of one's colleagues (Jones \& Hansen, 2015). Librarians who are not able to interpret emotional cues are at risk of behaving in ways that can elicit negative reactions in their colleagues and create stress in them because they are not able to understand the implications of their behavior. For example, a librarian who decides to only work a certain shift on the reference desk when others also want to work that shift, may not be able to alter his or her behavior when colleagues react with annoyance or anger. The practice of mindfulness makes the practitioner more sensitive to their own emotions, which has the effect of also 
The Potential of Mindfulness in Managing Emotions in Libraries

making them sensitive to the emotions of others. This allows the librarian to be more supportive emotionally when he or she upsets a colleague.

$$
\text { Compassion, Helpfulness, and Inclusion }
$$

Along with good communication, supportive helping behavior is important in the workplace. Having colleagues that are willing to help when it is needed can make a dramatic difference in the quality of one's work environment. Conversely, co-workers who are competitive and self-centered can make the workplace aversive and more difficult to effectively function in.

Mindfulness helps develop compassion, which makes people more prone to come to the help of others when they need it. The emphasis that mindfulness places on being focused in the present makes the librarian more self-aware and makes him or her more empathic and able to take the perspective of others more easily. Mindfulness fosters the development of positive emotions and helps people to let go of negative emotions through non-judgment and acceptance, since resistance tends to magnify negative emotions and increase stress levels. Mindfulness tends to generate positive emotions in the librarian because maintaining a present moment orientation makes the practitioner less prone to rumination about the past or worrying about the future. Positive thinking in turn makes the librarian more inclined to help colleagues because distressed individuals have been shown to be less likely to help others (Cameron \& Fredrickson, 2015).

One of the most common problems in the library working environment is the tendency to form cliques and develop in-groups and out-groups. Being excluded from office social circles can be highly stressful and make librarians who are not connected feel isolated and out of touch. When a librarian walks into a breakroom and all of the sudden conversation among colleagues stops, or is ignored in a meeting, it can make the person feel worse than if they were being confronted directly by a colleague. 
The Potential of Mindfulness in Managing Emotions in Libraries

Ostracism in the workplace is a subtle form of harassment or bullying but can have similarly detrimental effects and affect a librarian's work satisfaction, attendance, and health.

Mindfulness has been shown to be an effective way to reduce incidents of ostracism (Ramsey \& Jones, 2015). It makes the practitioner more sensitive to others and to the perspective of others. Ostracism occurs when a person fails to consider the social needs of another and is sometimes referred to as oblivious ostracism because of the person's unintentional neglect of a colleague. A librarian who practices mindfulness is likely to be more socially aware and interpersonally attuned to the needs of colleagues, making him or her less likely to engage in incidents of ostracizing behavior.

Social aggression such as ostracism can erode a librarian's self-esteem and lead to aggressive behavior on the part of the victim. This is particularly the case for librarians who have a fragile sense of self-esteem and are heavily invested psychologically in their work. For these librarians, their sense of selfworth becomes tied to specific results and experiences. When the librarian feels thwarted from achieving these ends, the individual may tend to feel that this has implications for him or her and feel personally vulnerable or threatened. Even if the provocation is ambiguous and merely perceived rather than actual, the result may be defensive behavior and overreaction in the form of anger or hostility.

This over-reactive behavior can be countered by the practice of mindfulness. When a librarian observes his or her thoughts with openness and without judgment or attachment, even hostile thoughts are allowed to pass. The person does not see incidents that happen in the workplace or elsewhere as necessarily aimed at them so that their self-esteem is not threatened. Their ego is not invested in specific outcomes so that they are better able to see ambiguous situations in a non-threatening way and to cope with social rejection (Heppner et al., 2008). The lack of ego may enable the librarian to feel less in competition with colleagues and more understanding and accepting of their perspective and behavior. 
The Potential of Mindfulness in Managing Emotions in Libraries

\section{Managing Performance Stress}

Colleagues are not the only source of stress in libraries. Librarians involved in public service roles experience social stress in working with the public. They and their performance are subject to continual evaluation and criticism from users. This is true both in working at the reference desk and providing library instruction in the classroom. Sometimes, the criticism they receive seems unjustified and unwarranted. Mindfulness can help alleviate the stress of social evaluation by reducing stress reactivity.

To test this, psychologists conducted an experiment in which they provided half of the subjects with a brief meditation training consisting of three 25 -minute audio recordings of guided mindfulness meditations (J. David Creswell, Pacilio, Lindsay, \& Brown, 2014). The other subjects received training in problem analysis. After receiving this training, the subjects were told by the experimenters that they had three minutes to prepare to give a five-minute speech addressing why they would be qualified to work as an administrative assistant in the department. As the subject delivered the speech, they were seated in front of two evaluators who were trained to be cold and rejecting. The evaluators repeatedly interrupted the speech with critical questions. The speech situation was purposely designed to create a high level of stress in the subjects. The results indicated that the subjects who received the brief mindfulness training were significantly less reactive to the speech situation. Their training helped to insulate them from the stress and enabled them to cope and manage the performance stress and audience criticism better.

\section{Conclusion}

Despite popular stereotypes, libraries and library work can be stressful and a source of emotional unease and distress for librarians. Continual change and upheaval, a demanding public, and difficult colleagues can all combine to make library work seem at times like an emotional roller coaster. With no indication that this situation is going to change any time in the foreseeable future, librarians have to find ways to cope with the emotional demands of the work. 
The Potential of Mindfulness in Managing Emotions in Libraries

Mindfulness offers an alternative to being buffeted about on the winds of change. Although it is a state of awareness that is not always easy to maintain, especially in challenging situations, it is easy to learn. With practice, it can be sustained so that it carries over into everyday situations at work in which it is important to manage the emotions and not get distracted by them or caught up in them. When librarians approach their work mindfully, they not only benefit from it themselves in the form of less stress and improved health, but also contribute to the overall health of the work environment by bringing a level of emotional calm and clarity to the library that it might not otherwise have. This in turn makes it a less stressful place for their colleagues to work which further helps to improve their emotional wellbeing.

Perhaps the most critical finding is the paradoxical nature of mindfulness. While it is a practice that is often done alone like other meditation practices and offers many benefits to the practitioner that are individual and personal, it can also lead to social and interpersonal improvement (Parker, Nelson, Epel, \& Siegel, 2015). Mindfully tuning into oneself allows one to monitor one's emotional reactions to the presence of another when interacting with them socially and make more appropriate responses as a result rather than merely reacting to them in a mindless automatic way. This has important implications for the library workplace, since work is an inherently social activity and the quality of work life depends to a large extent on the quality of workplace relationships.

The growing body of scientific research that suggests how beneficial meditation may be is beginning to make its way into the media. Workers, including librarians, are becoming more aware of and interested in mind-body practices that help reduce stress and improve resilience. Across the country, workplaces are responding to this interest by making mindfulness programs available to employees that provide education and training. Employers are beginning to understand that it is in their own interest to provide these kinds of services to their workers because of the many benefits of having 
The Potential of Mindfulness in Managing Emotions in Libraries

librarians who are relaxed, focused, emotionally healthy, and prosocial toward the public and to colleagues.

Libraries are just beginning to respond to the interest expressed by the public by making meditation spaces available to their users. But there is little evidence of libraries adopting large-scale mindfulness training programs like Google, Target, Intel, Aetna, General Mills, and other Fortune 500 companies have for their employees. This seems unfortunate, given the stressful nature of library work and the many potential benefits of practicing mindfulness to the organization.

Implementing Mindfulness

The simplicity of mindfulness makes it relatively easy to implement and practice in the library workplace, even without implementing a formal training program. Any activity that is normally performed during the course of the day can be performed mindfully, by bringing a quality of attention to the task that is relaxed, focused, and fully engaged. The simplicity of mindfulness makes it relatively easy to introduce into one's daily work routine. Take purposeful pauses at various times during the day to focus one's awareness on the present moment and take a few deep breaths to slow the chattering monkey mind. You can set a timer on your phone or purchase a mindfulness app to remind you. Similarly, routine activities at work such as walking to the restroom or the water cooler or to a meeting can be used as opportunities to practice, to let go of the cascade of thoughts and feelings coursing through our awareness and return attention to the sensations associated with movement to help ground us in the present moment. If you have difficulty in remembering to take purposeful pauses periodically throughout the workday, you can set a timer on your phone to ring hourly to remind you to pause and engage mindfully for a minute or two.

When you arrive at the meeting, see if you can pause for a moment and check in with yourself before speaking or taking notes. When someone else is speaking, resist the urge to check your phone or 
The Potential of Mindfulness in Managing Emotions in Libraries

to text. Instead, give your full attention to the person speaking, listening mindfully to their words and trying to understand their message and point of view before attempting to say anything (Ucok, 2006). When you speak, notice the person's reactions and observe your own reactions to them as they as speaking.

Lunch can be a time to attune mindfully. Even if you cannot get away from your computer, you can still take a few minutes to eat with awareness. Focus on smelling, chewing, tasting and swallowing each bite of food. Pause a few moments between bites. Then notice how it makes you feel and if you can tell when you have eaten enough (Jordan, Wang, Donatoni, \& Meier, 2014). Doing this will help you to be more present and less scattered.

Sitting at the reference desk, you can conduct a body scan to help you to relax and focus. Begin with becoming aware of sensations or feelings in the feet. Then direct your awareness to the shins and calves and notice how they feel. Move your attention to the upper legs, the quadriceps and hamstrings. Next, bring your attention to the pelvis and notice what you feel. From there, become aware of the abdomen. Then direct awareness to the arms and chest, observing how it feels. Finally, bring your attention to the shoulders, neck, and head. Be mindful of what you are feeling in this area. At any time during the scan, if you find the mind begins to generate thoughts or to drift away, bring it back to the body. This will help you become aware of any areas of stress or holding so you can release them and feel more grounded (Ditto, Eclache, \& Goldman, 2006).

Despite the simplicity of these practices, if done regularly they will strengthen the quality of attention and focus at work. By learning to stay oriented in the present, the librarian will begin to reap the emotional benefits that come with not ruminating about the past or worrying about the future. Libraries may continue in a state of upheaval and uncertainty, but librarians can find clarity and calm by practicing mindfulness and responding with equanimity to whatever the future holds. 
The Potential of Mindfulness in Managing Emotions in Libraries

References

Aikens, K. A., Astin, J., Pelletier, K. R., Levanovich, K., Baase, C. M., Park, Y. Y., \& Bodnar, C. M. (2014). Mindfulness goes to work: Impact of an online workplace intervention. Journal of Occupational and Environmental Medicine, 56(7), 721-731. doi:10.1097/JOM.0000000000000209

Cameron, C. D., \& Fredrickson, B. L. (2015). Mindfulness facets predict helping behavior and distinct helping-related emotions. Mindfulness, 6(5), 1211-1218. doi:10.1007/s12671-014-0383-2

Charoensukmongkol, P. (2013). The contributions of mindfulness meditation on burnout, coping strategy, and job satisfaction: Evidence from Thailand. Journal of Management \& Organization, 19(5), 544-558. doi:10.1017/jmo.2014.8

Chepenik, L. G., Cornew, L. A., \& Farah, M. J. (2007). The influence of sad mood on cognition. Emotion, 7(4), 802-811. doi:10.1037/1528-3542.7.4.802

Condon, P., Desbordes, G., Miller, W. B., \& DeSteno, D. (2013). Meditation increases compassionate responses to suffering. Psychological Science, 24(10), 2125-2127. doi:10.1177/0956797613485603

Creswell, J. D., Pacilio, L. E., Lindsay, E. K., \& Brown, K. W. (2014). Brief mindfulness meditation training alters psychological and neuroendocrine responses to social evaluative stress. Psychoneuroendocrinology, 44, 1-12. doi:10.1016/j.psyneuen.2014.02.007

Creswell, J. D., Way, B. M., Eisenberger, N. I., \& Lieberman, M. D. (2007). Neural correlates of dispositional mindfulness during affect labeling. Psychosomatic Medicine, 69(6), 560-565. doi:10.1097/PSY.0b013e3180f6171f

Ditto, B., Eclache, M., \& Goldman, N. (2006). Short-Term Autonomic and Cardiovascular Effects of Mindfulness Body Scan Meditation. Annals of Behavioral Medicine, 32(3), 227-234. doi:10.1207/s15324796abm3203_9

Grecucci, A., De Pisapia, N., Thero, D. K., Paladino, M. P., Venuti, P., \& Job, R. (2015). Baseline and strategic effects behind mindful emotion regulation: Behavioral and physiological investigation. PLOS ONE, 10(1).

Gross, J. J., \& Levenson, R. W. (1997). Hiding feelings: The acute effects of inhibiting negative and positive emotion. Journal of Abnormal Psychology, 106(1), 95-103. doi:10.1037/0021843X.106.1.95

Heppner, W. L., Kernis, M. H., Lakey, C. E., Campbell, W. K., Goldman, B. M., Davis, P. J., \& Cascio, E. V. (2008). Mindfulness as a means of reducing aggressive behavior: Dispositional and situational evidence. Aggressive Behavior, 34(5), 486-496. doi:10.1002/ab.20258

Hölzel, B. K., Lazar, S. W., Gard, T., Schuman-Olivier, Z., Vago, D. R., \& Ott, U. (2011). How does mindfulness meditation work? Proposing mechanisms of action from a conceptual and neural perspective. Perspectives on Psychological Science, 6(6), 537-559. doi:10.1177/1745691611419671

Hülsheger, U. R., Alberts, H. J. E. M., Feinholdt, A., \& Lang, J. W. B. (2013). Benefits of mindfulness at work: The role of mindfulness in emotion regulation, emotional exhaustion, and job satisfaction. Journal of Applied Psychology, 98(2), 310-325. doi:10.1037/a0031313

Jones, S. M., \& Hansen, W. (2015). The impact of mindfulness on supportive communication skills: Three exploratory studies. Mindfulness, 6(5), 1115-1128. doi:10.1007/s12671-014-0362-7

Jordan, C. H., Wang, W., Donatoni, L., \& Meier, B. P. (2014). Mindful eating: Trait and state mindfulness predict healthier eating behavior. Personality and Individual Differences, 68, 107-111. doi:10.1016/j.paid.2014.04.013 
The Potential of Mindfulness in Managing Emotions in Libraries

Kemeny, M. E., Foltz, C., Cavanagh, J. F., Cullen, M., Giese-Davis, J., Jennings, P., . . Ekman, P. (2012). Contemplative/emotion training reduces negative emotional behavior and promotes prosocial responses. Emotion, 12(2), 338-350. doi:10.1037/a0026118

10.1037/a0026118.supp (Supplemental)

Khisty, C. J. (2010). The Practice of Mindfulness for Managers in the Marketplace. Systemic Practice \& Action Research, 23(2), 115-125. doi:10.1007/s11213-009-9151-y

Lindsay, E. K., \& Creswell, J. D. (2015). Back to the Basics: How Attention Monitoring and Acceptance Stimulate Positive Growth. Psychological Inquiry, 26(4), 343-348. doi:10.1080/1047840X.2015.1085265

Luberto, C. M., Cotton, S., McLeish, A. C., Mingione, C. J., \& O’Bryan, E. M. (2014). Mindfulness skills and emotion regulation: The mediating role of coping self-efficacy. Mindfulness, 5(4), 373-380. doi:10.1007/s12671-012-0190-6

Lueke, A., \& Gibson, B. (2016). Brief mindfulness meditation reduces discrimination. Psychology of Consciousness: Theory, Research, and Practice, 3(1), 34-44. doi:10.1037/cns0000081

Matteson, M. L., Chittock, S., \& Mease, D. (2015). In Their Own Words: Stories of Emotional Labor from the Library Workforce. Library Quarterly, 85(1), 85-105.

Niemiec, C. P., Brown, K. W., Kashdan, T. B., Cozzolino, P. J., Breen, W. E., Levesque-Bristol, C., \& Ryan, R. M. (2010). Being present in the face of existential threat: The role of trait mindfulness in reducing defensive responses to mortality salience. Journal of Personality and Social Psychology, 99(2), 344-365. doi:10.1037/a0019388

Ortner, C. N. M., Kilner, S. J., \& Zelazo, P. D. (2007). Mindfulness meditation and reduced emotional interference on a cognitive task. Motivation and Emotion, 31(4), 271-283. doi:10.1007/s11031007-9076-7

Podsakoff, P.M., MacKenzie, S.B., Moorman, R.H., and Fetter, R.R. (1990). Transformational leadership behaviors and their effects on followers' trust in leader, satisfaction, and organizational citizenship behaviors. Leadership Quarterly, 1 (2), 107-142.

Papies, E. K., Barsalou, L. W., \& Custers, R. (2012). Mindful attention prevents mindless impulses. Social Psychological and Personality Science, 3(3), 291-299. doi:10.1177/1948550611419031

Philippot, P., \& Heeren, A. (2013). Mindfulness-based interventions: The dialectic of changing emotions by accepting them. In D. Hermans, B. Rimé, \& B. Mesquita (Eds.), Changing emotions. (pp. 217222). New York, NY, US: Psychology Press.

Ramsey, A. T., \& Jones, E. E. (2015). Minding the interpersonal gap: Mindfulness-based interventions in the prevention of ostracism. Consciousness and Cognition: An International Journal, 31, 24-34. doi:10.1016/j.concog.2014.10.003

Semmer, N. K., Messerli, L., \& Tschan, F. (2016). Disentangling the components of surface acting in emotion work: Experiencing emotions may be as important as regulating them. Journal of Applied Social Psychology, 46(1), 46-64. doi:10.1111/jasp.12364

Smyth, L. F. (2012). Escalation and mindfulness. Negotiation Journal, 28(1), 45-72. doi:10.1111/j.15719979.2011.00325.x

Ucok, O. (2006). Transparency, communication and mindfulness. Journal of Management Development, 25(10), 1024-1028. doi:10.1108/02621710610708676 